\title{
Relationship of Muscle Strength for Knee Extension to Walking Capacity in Patients with Spastic Hemiparesis
}

\author{
Ryuichi Nakamura, Tooru Hosokawa and Ichiro Tsuji \\ Institute of Rehabilitation Medicine, Tohoku University \\ School of Medicine, Narugo, Miyagi 989-68
}

\begin{abstract}
Nakamura, R., Hosokawa, T. and Tsuji, I. Relationship of Muscle Strength for Knee Extension to Walking Capacity in Patients with Spastic Hemiparesis. Tohoku J. exp. Med., 1985, 145 (3), 335-340_- Muscle strength for knee extension, both isokinetic and isometric, and walking capacity, maximum velocity and walking rate, were examined in 11 post-stroke hemiparetic patients. The degree of spasticity of the affected lower extremity was not related to the isokinetic and isometric torques, or to the walking capacity. Although both the isokinetic and isometric torques decreased on the affected side compared to the non-affected side, the rate of decrease was remarkable in isokinetic torque at fast velocities. The walking capacity was well correlated with isokinetic torque of the affected side at fast velocities but not isometric torques. These results suggest that reduction of muscle strength at rapid movements is an essential feature of spastic paresis and is primary cause of motor disabilities such as impaired locomotor function.

muscle strength; spasticity; walking capacity; hemiparesis
\end{abstract}

One of the widely accepted premises in spastic paralysis is that spasticity limits voluntary movements and thus leads to motor disabilities. Clinically, however, there is no strict relationship between the degree of spasticity and the severity of paralysis. Recent studies suggest that a common feature in the majority of spastic patients is functional impairment of fast movements (Hallett 1979 ; Knutsson and Martensson 1980) and of rapid repetitive movements (Sahrmann and Norton 1977), and prolonged motor time, latency from electromyographic activities of prime mover muscle to initiation of actual movement (Nakamura and Taniguchi 1977).

Also other studies have indicated that there is a high correlation between isokinetic torque of the paretic knee and locomotor function in post-stroke patients (Hamrin et al. 1982), and in patients with spinal paraparesis motor time of the rectus femoris muscle for knee extension is a highly predictive measure for locomotor function but not maximum isometric strength of knee extension (Nakamura and Sajiki 1983). However, as for the motor disability of peripheral origin such as osteoarthritis of the knee and below-knee amputation, results on the

Received for publication, August 10, 1984. 
relation of muscle strength, either isokinetic or isometric, to walking capacity are still controversial (Lankhorst et al. 1982 ; Renstrom et al. 1983).

Thus, there remain two questions ; whether isokinetic strength at fast velocities or isometric one is specifically affected in patients with spastic paralysis due to supraspinal lesion and of which strength for knee extension is closely tied to locomotor function. In this study we measured walking capacity and muscle strength, both isokinetic and isometric, in patients with post-stroke hemiparesis, and attempted to solve the questions above mentioned.

\section{MEthods}

Eleven hemiparetic patients due to cerebro-vascular disease participated in the study. Ten patients were males with mean age of 53.8 (range : 27-77) years and one female aged 50 years. The mean time from the onset to the examination was $4.0(0.5-22.5)$ months. All patients showed muscular hypertone from mild to moderate degree on the lower extremity of the affected side. Hyperactivity of the patellar tendon reflex (PTR) on the affected side was clinically classified into three grades.

As for variables of walking capacity, time (sec) required to walk $10 \mathrm{~m}$ as fast as possible on flat floor without cane and/or orthosis, and the number of steps over $10 \mathrm{~m}$ were measured. They were expressed in terms of velocity $(\mathrm{m} / \mathrm{min})$ and walking rate (steps $/ \mathrm{min})$. Eight patients performed the trial three times and the fastest record was used as data. The remaining three patients took more than 30 sec to walk $10 \mathrm{~m}$ and thus they carried out only one trial.

For the measurement of maximum muscle strength an isokinetic dynamometer (Cybex II, Lumex Inc., New York) was used. The patients sat on a chair with the hip and the knee flexion of $90^{\circ}$ and the legs hanging over the edge of the chair. The dynamometer was rigidly fixed to the chair. The dynamometer arm was attached to the leg at the ankle. Isokinetic strength was measured as the torque $(\mathrm{kg} \cdot \mathrm{m})$ during maximum knee extension movements starting from $90^{\circ}$ flexion with constant angular velocities which were preset at 30,90 and $180^{\circ} / \mathrm{sec}$. Isometric strength was measured as the torque during maximum isometric contraction for knee extension at knee angles 30,60 and $90^{\circ}$ from fully extended position. Three trials were carried out at each velocity and angle, and the highest torques among the trials were used as data in each patient. The measurements were always performed first on the affected side and then on the non-affected side. The order of isokinetic and isometric torque measurements was randomly assigned among the patients.

\section{RESULTS}

Overall mean and S.D. of velocity and walking rate were $55.4 \pm 35.0(9.6-115$. 2) $\mathrm{m} / \mathrm{min}$ and $106.3 \pm 34.8$ (66-162) steps/min, respectively. The degree of PTR was not correlated with velocity, walking rate, or any measures of the muscle strength on the affected side (Table 1).

Table 2 shows mean and S.D. of the isokinetic and the isometric torques. For all measures the torques of the affected side were significantly smaller than those of the non-affected side. Both on the affected and non-affected side there was a trend that the faster the angular velocities were, the smaller the isokinetic torque, and also the more the knee extended, the smaller the isometric torque. However, this trend was more remarkable on the affected side, which was clearly demon- 
TABLE 1. Correlation coefficient of spasticity versus walking capacity and muscle strength of the affected side

\begin{tabular}{lccccccc}
\hline Velocity & $\begin{array}{c}\text { Walking } \\
\text { rate }\end{array}$ & $\begin{array}{c}\text { IK } \\
30\end{array}$ & $\begin{array}{c}\text { IK } \\
90\end{array}$ & $\begin{array}{c}\text { IK } \\
180\end{array}$ & $\begin{array}{c}\text { IM } \\
90\end{array}$ & $\begin{array}{c}\text { IM } \\
60\end{array}$ & $\begin{array}{c}\text { IM } \\
30\end{array}$ \\
\hline 0.161 & 0.249 & 0.040 & 0.007 & 0.082 & 0.099 & 0.023 & 0.005 \\
\hline & $n=11$. & $p<0.05:$ & 0.602 \\
IK : Isokinetic torque, 30, & $90,180:$ & angular velocity (degrees/sec), & \\
respectively. \\
IM : Isometric torque, $90,60,30:$ angle of the knee (degrees), respec- \\
tively.
\end{tabular}

TABLE 2. Overall mean and S.D. (in parenthesis) of isokinetic and isometric torque

\begin{tabular}{lcccc}
\hline & Affected side & Non-affected side & Difference & Ratio (A/N) \\
\hline IK $30^{\circ} / \mathrm{sec}$ & $5.0(3.9)$ & Isokinetic torque $(\mathrm{kg} \cdot \mathrm{m})$ & \\
IK $90^{\circ} / \mathrm{sec}$ & $2.1(1.9)$ & $6.6(3.5)$ & $4.4(3.7)$ & 0.49 \\
IK $180^{\circ} / \mathrm{sec}$ & $0.7(0.7)$ & $4.1(2.7)$ & $3.4(2.8)$ & 0.17 \\
& & Isometric torque (kg $\cdot \mathrm{m})$ & \\
IM $90^{\circ}$ & $7.1(5.7)$ & $12.8(6.5)$ & $5.7(5.2)$ & 0.56 \\
IM $60^{\circ}$ & $5.6(4.5)$ & $9.8(5.4)$ & $4.2(4.7)$ & 0.57 \\
IM $30^{\circ}$ & $1.4(2.2)$ & $3.7(2.4)$ & $2.3(2.6)$ & 0.38 \\
\hline
\end{tabular}

IK : Isokinetic contraction, IM : Isometric contraction.

strated by the decrease of $\mathrm{A} / \mathrm{N}$ ratio. Both for the isokinetic and isometric torques there was no significant correlation between the affected and the nonaffected side except in the isometric torque at $90^{\circ}$ flexion of the knee $(p<0.05)$.

Table 3 presents the correlation matrices of variables on the affected and non-affected sides. Variables representing the isokinetic and isometric torques were significantly correlated with each other on both sides. However, there were no significant correlations between the variables representing the walking capacity, namely, velocity and walking rate, and the torques of the non-affected side. On the contrary, the torques of the affected side were significantly correlated with the walking capacity except the isometric torque at $30^{\circ}$.

Stepwise regression analyses of the torques to the walking capacity extracted the isokinetic torque at angular velocity of $90^{\circ} / \mathrm{sec}$ as a significant predictor of velocity $(p<0.001)$ and the isokinetic torque at angular velocity of $180^{\circ} / \mathrm{sec}$ as that of walking rate $(p<0.001)$. These variables explained $75.6 \% \quad(R=0.870$, $\left.R^{2}=0.756\right)$ and $72.7 \%\left(R=0.853, R^{2}=0.727\right)$ of total variance, respectively. Regression coefficients of other variables did not reach at 0.05 level of statistical significance. These results pointed out that isokinetic torques for knee extension at fast angular velocities of the affected side has a highly predictable value for walking capacity in patients with spastic paresis. 
TABLE 3. Correlation matrices among the variables. Upper triangular: Affected side, Lower triangular: Non-affected side.

\begin{tabular}{lcccccccc}
\hline & Velocity & $\begin{array}{c}\text { Walking } \\
\text { rate }\end{array}$ & $\begin{array}{c}\text { IK } \\
30\end{array}$ & $\begin{array}{c}\text { IK } \\
90\end{array}$ & $\begin{array}{c}\text { IK } \\
180\end{array}$ & $\begin{array}{c}\text { IM } \\
90\end{array}$ & $\begin{array}{c}\text { IM } \\
60\end{array}$ & $\begin{array}{c}\text { IM } \\
30\end{array}$ \\
\hline Velocity & & $.867 \dagger$ & $.794 \dagger$ & $.870 \dagger$ & $.847 \dagger$ & $.759 \dagger$ & $.749 \dagger$ & .595 \\
Walking Rate & $.867 \dagger$ & & $.666 \dagger$ & $.738 \dagger$ & $.853 \dagger$ & $.635^{*}$ & $.609^{*}$ & $.646^{*}$ \\
IK 30 & .111 &.- .442 & & $.820 \dagger$ & $.733^{*}$ & $.975 \dagger$ & $.960 \dagger$ & $.810 \dagger$ \\
IK 90 & .042 &.- .180 & $.841 \dagger$ & & $.896 \dagger$ & $.852 \dagger$ & $.841 \dagger$ & $.692^{*}$ \\
IK 180 & -.064 &.- .251 & $.665^{*}$ & $.896 \dagger$ & & $.711 \dagger$ & $.686^{*}$ & $.602^{*}$ \\
IM 90 & .436 & .195 & $.693 \dagger$ & $.804 \dagger$ & $.704^{*}$ & & $.988 \dagger$ & $.859 \dagger$ \\
IM 60 & .195 & -.062 & $.773 \dagger$ & $.872 \dagger$ & $.832 \dagger$ & $.934 \dagger$ & & $.845 \dagger$ \\
IM 30 & .175 & -.099 & $.778 \dagger$ & $.852 \dagger$ & $.819 \dagger$ & $.868 \dagger$ & $.954 \dagger$ & \\
\hline
\end{tabular}

$n=11 .{ }^{*} p<0.05, \dagger p<0.01$.

\section{Discussion}

The present study indicated that there was no significant correlation between the degree of spasticity on the affected lower extremity and the walking capacity, measured as velocity and walking rate, of hemiparetic patients who could anyhow walk without aids. Also spasticity was not correlated with the muscle strength measured either isokinetically or isometrically. It seems that spasticity as a positive sign is not a limiting factor of motor disability, but decreased muscle strength as a negative sign is related to motor disability. Although both the isokinetic and isometric strength decreased on the affected side compared to the non-affected side, the rate of decrease was more evident in isokinetic strength at fast velocities than isometric strength as shown by the decreased $\mathrm{A} / \mathrm{N}$ ratio. In other words, the faster the movement became, the less the isokinetic strength in the paretic muscle. This result coincided with other studies on spastic paresis (McComas et al. 1973; Sahrmann and Norton 1977; Knutsson and Martensson 1980.) In normal subjects isokinetic strength for knee extension is correlated with isometric one, but the correlation becomes rather low when the velocity of movements is high (Knapik and Ramos 1980). Studies concerning the speedstrength relationship suggested the independence between movement speed and isometric strength (Lagasse 1979), and separate control mechanisms for speed and force were proposed (Brooks and Stoney 1971). If these presumptions are valid, capsular lesion would damage mainly the system that carries out fast movements or rapid tension development of muscle, but not the other one which is concerned with maximum isometric strength.

Another finding in the present study was that isokinetic strength for knee extension at fast velocities on the affected side had a predictable value for walking capacity of patients. This result confirms previous hypothesis that the rate of rapid tension development for knee extension is critical for locomotor function in 
patients with spinal paraparesis (Nakamura and Sajiki 1983). Although the bipedal locomotion of human is a very complex phenomenon performed by synergic action of many muscles, it would be of some values to discuss the present results from biomechanical point of view. In normal walking the knee flexes and extends about $60^{\circ}$ to $70^{\circ}$ during 50 percent of one walking cycle (Murray et al. 1966 ; Murray 1967 ; Knutsson and Richards 1979). Assuming the walking rate as $120 \mathrm{steps} / \mathrm{min}$, then the knee should move with angular velocities of $240^{\circ}$ to $280^{\circ} /$ sec. The rapid knee extension starts during the deceleration period of swing phase. Electromyographic analysis of normal walking has shown that the quadriceps femoris muscle becomes active from the deceleration and the heel contact, and continues to be active till the midstance (Dubo et al. 1976; Knutsson and Richards 1979). The rapid knee extension during the deceleration period should be performed by concentric contraction of the muscle, of which strength would be a determinant of walking velocity and step length, and probably walking rate. It is well known that step length of the affected side is very short and walking rate is low in hemiplegic patients. This phenomenon is definitely related to paresis, for their quadriceps femoris muscle could not produce movements at fast angular velocities of the knee as shown in this study.

\section{References}

1) Brooks, V.B. \& Stoney, D. (1971) Motor mechanisms: the role of the pyramidal system in motor control. Ann. Rev. Physiol., 33, 337-392.

2) Dubo, H.I.C., Peat, M., Winter, D.A., Quanbury, A.O., Hobson, D.A., Steinke, T. \& Reimer, G. (1976) Electromyographic temporal analysis of gait: normal human locomotion. Arch. phys. Med. Rehabil., 57, 415-420.

3) Hallett, M. (1979) Ballistic elbow flexion movement in patients with amyotrophic laterl sclerosis. J. Neurol. Neurosurg. Psychiat., 32, 232-237.

4) Hamrin, E., Eklund, G., Hillgren, A.K., Borges, O., Hall, J. \& Hellstrom, O. (1982) Muscle strength and balance in post-stroke patients. Upsala J. med. Sci., 87, 11-26.

5) Knapik, J.J. \& Ramos, M.U. (1980) Isokinetic and isometric torque relationships in the human body. Arch. phys. Med. Rehabil., 61, 64-67.

6) Knutsson, E. \& Martensson, A. (1980) Dynamic motor capacity in spastic paresis and its relation to prime mover dysfunction, spastic reflexes and antagonist co-activation. Scand. J. Rehabil. Med., 12, 93-106.

7) Knutsson, E. \& Richards, C. (1979) Different types of disturbed motor control in gait of hemiparetic patients. Brain, 102, 405-430.

8) Lagasse, P.P. (1979) Prediction of maximum speed of human movement by two selected muscular coordination mechanisms and by maximum static strength. Percept. Motor Skills, 49, 151-161.

9) Lankhorst, G.J., van de Stadt, R.J., van der Korst, J.K., Hinlopen-Bonrath, E., Griffioen, F.M.M. \& de Boer, W. (1982) Relationship of isometric knee extension torque and functional variables in osteoarthrosis of the knee. Scand. J. Rehabil. Med., 14, 7-10.

10) McComas, A.J., Sica, R.E.P, Upton, A.R.M. \& Aguilera, N. (1973) Functional changes in motoneurones of hemiparetic patients. J. Neurol. Neurosurg. Psychiat., 36, 183-193.

11) Murray, M.P. (1967) Gait as a total pattern of movement. Amer. J. phys. Med., 46, 
290-333.

12) Murray, M.P., Kory, R.C., Clarkson, B.H. \& Sepic, S.B. (1966) Comparison of free and fast speed walking patterns of normal men. Amer. J. phys. Med., 45, 8-24.

13) Nakamura, R. \& Sajiki, N. (1983) Motor reaction time as a measure of functional impairment in paraplegia. In : Proc. Restorative Neurology in the Central and Peripheral Nervous System, Integrated Electrophysiological Evaluations, Venice, Italy, p. 103.

14) Nakamura, R. \& Taniguchi, R. (1977) Reaction time in patients with cerebral hemiparesis. Neuropsychology, 15, 845-848.

15) Renstrom, P., Grimby, G. \& Larsson, E. (1983) Thigh muscle strength in below-knee amputees. Scand. J. Rehabil. Med., Suppl., 9, 163-173.

16) Sahrmann, S.A. \& Norton, B.J. (1977) The relationship of voluntary movement to spasticity in the upper motor neuron syndromes. Ann. Neurol., 2, 460-465. 